\title{
Agôn
}

Revue des arts de la scène

Critiques | Saison 2012-2013

\section{Les Criminels de Ferdinand Bruckner, mise en scène de Richard Brunel}

La volonté du visible

\section{Caroline Châtelet}

\section{(2) OpenEdition \\ Journals}

Édition électronique

URL : http://journals.openedition.org/agon/2561

DOI : 10.4000/agon.2561

ISSN : 1961-8581

Éditeur

Association Agôn

Référence électronique

Caroline Châtelet, « Les Criminels de Ferdinand Bruckner, mise en scène de Richard Brunel », Agôn [En ligne], Critiques, mis en ligne le 02 avril 2013, consulté le 23 septembre 2020. URL : http://

journals.openedition.org/agon/2561 ; DOI : https://doi.org/10.4000/agon.2561

Ce document a été généré automatiquement le 23 septembre 2020.

Association Agôn et les auteurs des articles 


\section{Les Criminels de Ferdinand Bruckner, mise en scène de Richard Brunel}

La volonté du visible

Caroline Châtelet

\section{RÉFÉRENCE}

Les Criminels de Ferdinand Bruckner, mise en scène Richard Brunel avec Cécile Bournay, Angélique Clairand, Clément Clavel, Murielle Colvez, Claude Duparfait, François Font, Mathieu Genet, Marie Kauffmann, Martin Kipfer, Valérie Larroque, Sava Lolov, Claire Rappin, Laurence Roy, Thibault Vinçon ; avec la participation de Nicolas Hénault, Gilbert Morel - Théâtre national de la Colline - du 8 février au 2 mars 2013. www.colline.fr / 0144625252 / 15 rue Malte-Brun, Paris $20^{\circ}$ en tournée au Théâtre National de Toulouse - du 13 au 15 mars 2013 / à la Comédie de Clermont-Ferrand - du 27 au 28 mars 2013 / au Théâtre du Nord, Lille - du 4 au 12 avril 2013.

1 « Nous considérons les choses de l'extérieur, et notre erreur est là. Nous accordons à un verdict une valeur morale, officielle. Or la morale s'applique à la vie, alors qu'un verdict, une condamnation, dépendent d'un tout autre contexte, le contexte de la justice. C'est un contexte en soi. Un monde à des années-lumière de la vie, fermé sur lui-même, pétrifié depuis des siècles. » Lorsque à la fin du troisième acte des Criminels le personnage de Kummerer dit cela, il prend acte du divorce consommé entre la justice et les citoyens et décide de se replier sur ses écrits. Bientôt, il sera interrompu par trois hommes venus le chercher. Mais pour l'heure, le jeune étudiant en philosophie dont la fiancée Olga a été jeté en prison pour infanticide après avoir été sommairement jugée, est encore seul. Sa position d'isolement - debout dans une quasi-obscurité il est penché sur son ordinateur - est renforcée par son visage grimé de blanc, ainsi que par une lumière venant accentuer celle émise par l'écran d'ordinateur, poursuite soulignant plus qu'elle ne révèle son teint blafard. Une image finale qui suffit à saisir le geste de mise en scène de Richard Brunel. Car créant cette pièce, qui raconte avec précision la 
confrontation des différents habitants d'un immeuble dans l'Allemagne des années vingt à une implacable machine judiciaire, le directeur de la Comédie de Valence opte pour un surlignement permanent. Un geste d'obscénité entendue comme «visibilité totale des choses ${ }^{1}$.»

2 Appliquée au théâtre, cette obscénité prend les allures d'un volontarisme dramaturgique, dont l'objectif affiché est de dire tout au long du spectacle au spectateur ce qu'il doit voir² :

« (...) l'intermédiaire esthétique - en tant qu'espace de doute et d'interlocution - se voit dénié toute existence et toute valeur (on voudrait passer sans procès de l'effet à la cause) : «Ce que le spectateur doit voir est ce que le metteur en scène lui fait voir ", écrit Jacques Rancière dans Le Spectateur émancipé qui rappelle plus loin que la performance «n'est pas la transmission du savoir ou du souffle de l'artiste au spectateur. Elle est cette troisième chose dont aucun n'est propriétaire, dont aucun ne possède le sens, qui se tient entre eux, écartant toute transmission à l'identique, toute identité de la cause et de l'effet ${ }^{3}$.»

Devant cette proposition certes maitrisée mais par trop univoque, demeure, outre le plaisir d'une distribution alléchante, l'intérêt de découvrir une pièce brillante. Qui, écrite en 1928, raconte autant le divorce consommé entre une institution judiciaire et ses bénéficiaires qu'elle annonce les chaos à venir. Et en exposant avec acuité et méthodisme les ravages d'une justice dont les enjeux se situent à mille lieux de la réalité (et de la misère sociale) de ses citoyens, Les Criminels aborde la question, elle, toujours d'actualité, d'une alternative possible face à l'aveuglement d'institutions oublieuses du bien commun.

\section{NOTES}

1. Jean Baudrillard, Mots de passe, Paris, Le Livre de Poche, coll. «Biblio Essais », 2004, p. 36.

2. La notion d'obscénité et de dramaturgie est développée dans De quoi la dramaturgie est-elle le nom? Lexique sur la dramaturgie (titre provisoire), ouvrage collectif rédigé par l'équipe d'Agôn, à paraître (bientôt ! !).

3. Barbara Métais-Chastanier, De quoi la dramaturgie est-elle le nom ? Lexique sur la dramaturgie (titre provisoire), Ibid. 